\title{
The review of food safety inspection system based on artificial intelligence, image processing, and robotic
}

\author{
Tzu-Chia CHEN ${ }^{1 *}$ (D), Shu-Yan YU ${ }^{1}$
}

\begin{abstract}
The main target of the current study is to review the latest developments in accurate, reliable, and low-cost non-contact or remote techniques, including the usage of artificial intelligence (AI)-based methods, image processing (IP) system, and sensor technology for quality assessment in the food industry (FI). The IP systems and AI can be used for various purposes, such as classifying products based on size and shape, detecting product defects, the presence of microbes, and grading food quality. The sensor technology is now highly developed to assess food products' quality and safety due to the dramatic growth of nanotechnology and biotechnology. Also, in this paper, it was tried to examine the role of robots in the FI and discusses the advantages and disadvantages of using them in the FI.
\end{abstract}

Keywords: food safety, technology, machine, robotics.

Practical Application: We aimed to review the latest developments in the usage of artificial intelligence based methods, image processing system, and sensor technology for quality assessment in the food industry. Outr other target was to examine the role of robots in the food industry and discusses the advantages and disadvantages of using them in the food industry.

\section{Introduction}

With increasing living standards, advances in technology and image processing (IP), the increasing importance of food quality, the food industries are turning to new technologies (Molajou et al., 2021a). On the other hand, as the population grows and consumer expectations rise more than ever, and their awareness, the food industry (FI) needs fast and accurate analytical techniques (European Communities, 2005). Producers need to market higher quality food and agricultural products to meet the complex demands of consumers (Pouladi et al., 2020). Food safety (FS) is concerned with the food's health and hygiene (Beyts et al., 2017; Bisgin et al., 2018).

The idea of "FS" is to provide conditions and methods through which the quality of food is maintained in order to prevent foodborne diseases. In other words, it is called FS to ensure that food does not contain microbial, chemical, and physical contaminants during transportation and preparation, and storage and does not cause disease to consumers. FS is sometimes confused with food security, although the two have separate meanings. FS refers to the health and usability of food so that it does not make the consumer sick, but FS refers to the ubiquity and availability of food so that there are enough food and needs. Satisfy the consumer's nutrition (Bouzembrak et al., 2018). Food and Agriculture Organization (FAO) has claimed that unhealthy food kills 2 million people a year, most of them are children. Foods that contain harmful chemicals, parasites, viruses, or bacteria are responsible for more than 200 types of disease. Many studies emphasized that new FS threats are constantly emerging. These new threats are i) changes in the environment, ii) changes in food production, distribution, and consumption, iii) new and emerging pathogens, and iv) antimicrobial food resistance (Buratti et al., 2017). Increased travel and trade have also increased the likelihood of international pollution.

FS is increasingly globalizing, and the need to strengthen FS systems is increasingly evident among countries. With the spread of technology, the usage of hormones, antibiotics, pesticides, and additives in FI in developing countries has grown significantly, leading to undeniable effects on human health, including congenital anomalies and cancers, especially in children. While most microorganisms do not cause disease, dangerous microorganisms are widespread in soil, water, animals, and humans (Chu et al., 2018). These microorganisms are present on hands, cleaning cloths, especially food chopping boards, and the slightest contact can transfer them to food and cause foodborne illness. The supply of food is increasingly globalizing, and this requires increased attention to the FS system among countries (Fuentes et al., 2019; Fuertes et al., 2016).

For this reason, the World Health Organization (WHO) has set its motto in 2015 to improve FS from farm to fork (always and everywhere) to help countries prevent, identify and treat foodborne illness. In this regard, international standards and guidelines should be developed to cover major food processes. WHO and FAO, through their global information network, warns countries about FS. Analysis of foodborne illness data around the world has shown that the majority of disease-related outbreaks occur during food preparation in small businesses, restaurants, residential areas, and other food preparation areas (García-Esteban et al., 2018). 
Despite the increase in the number of people receiving food training, a high proportion of food poisoning prevalence is still due to poor food management practices. The difference between functional knowledge and its impact on food management operations indicates that many health education programs were designed using the knowledge-attitude-behavior (KAB) model. The KAB model assumes that a person's behavior depends on their knowledge (Ghafir et al., 2008). Therefore, providing more information leads to changes in attitude and consequently performance. Many researchers have criticized the effectiveness of the KAB model in food health education, and so much knowledge has been created about safety issues, so there may not be positive changes in people's behavior.

It is obvious that the modeling is measured to forecast the final product's quality based on various parameters (Guzmán et al., 2019; Iqbal et al., 2017). Some new approaches, which include the usage of automated analysis techniques (AATs) along with artificial intelligence (AI), like computer vision (CV), have been expanded to modeling and evaluate the quality parameters in drink and food. The mentioned methods are possible to have objective, accurate, consistent, and reliable results (Gonzalez Viejo et al., 2019). These approaches can also involve the usage of multi-sensor systems or an array of sensors, usually combined with other AI methods to evaluate the quality parameters.

In recent years, the usage of robotics in the beverage and food industries has also increased because they have some main advantages that they are reliable, do not get tired, and the work done may be done with high accuracy in less time. One of the main applications of robotics in the beverage and food industries is production, selection, packaging, palletizing, and placement (Kaplan \& Haenlein, 2019; Liatsis et al., 2009). The tasks of robots or operations may be simple or repetitive, or adaptable and more complex. The latter requires the integration of other AI approaches (like ML and CV) for ongoing training and learning to perform more advanced operations (Ireri et al., 2019).

The term AI refers to machines that are built to think, make decisions, solve problems, and behave in a way that humans make decisions, apart from being able to progress through selflearning. Currently, there is theoretically generalized AI, but only weak or practical AI has been created (Misra et al., 2020; Nica et al., 2020; Molajou et al., 2021b).

The general concept of AI-based approaches may consist of various branches (like $\mathrm{CV}$ and $\mathrm{ML}$ ). It can also involve the usage of biometrics, sensors, and robotics (see Figure 1). However, some research institutes and companies have combined them with AI departments for more automated applications such as quality control, inspection, and the most common casting or beverage dispensing machine (Patrício \& Rieder, 2018; Nourani et al., 2019).

\section{Material and methods}

The IP systems can be used for different purposes, such as classifying products based on size and shape, the presence of microbes, and grading food quality. The IP systems in the FI have also shown great potential. Today, a wide range of inspections have been proposed in which microbiological and chemical

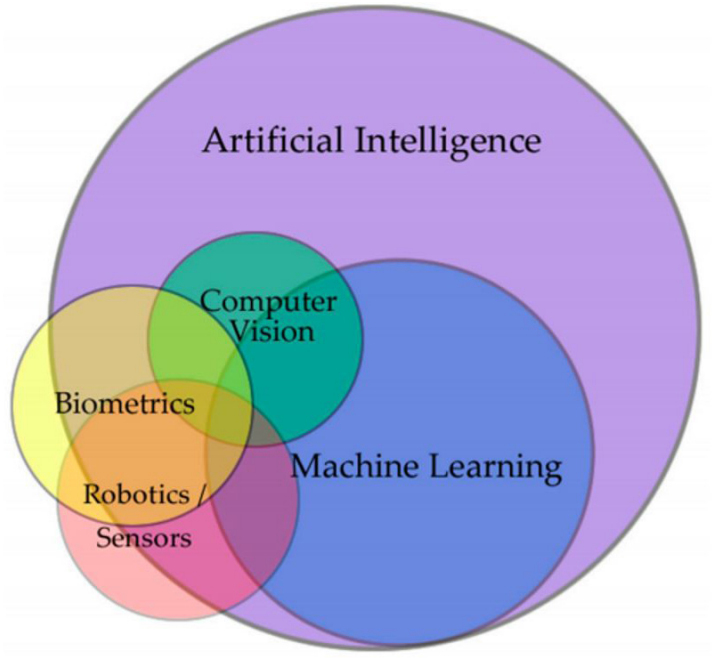

Figure 1. Van diagram indicating the relation between AI and other integrated approaches.

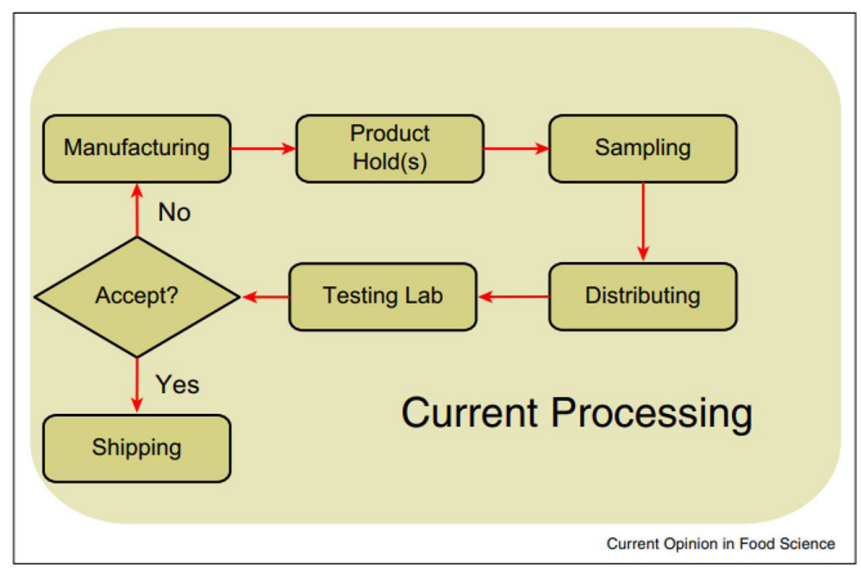

Figure 2. The FI carries out FS testing and control.

analyses have been introduced to assess the safety or quality of food products and raw materials.

FS relies on regulatory sampling regimes and inspections (Pérez Santín et al., 2021). In fact, the FS management system, although mainly based on the good design of processes, products, and procedures, is the final product test, is considered a measure of production process control (see Figure 2). This is obvious in the case of microbiological FS, which must be followed by specific microbiological analysis.

Food quality is measured by internal and external parameters (Qi, 2020). External parameters include surface color, texture, opacity, or defects, which are controlled and classified by workers. Internal parameters are hardness and softness, contents, acidity, which are evaluated by conventional techniques. Some characteristics such as sweetness and flavor, FS (e.g., the presence of pathogenic bacteria on the product, its contamination with animal faces, the presence of pesticides on the product, and other hazardous substances) are factors that affect the reliability of the food. Examining all of these in the food market today using old techniques is costly and time-consuming (Romero et al., 2018; 
Sun et al., 2019). Unlike traditional methods of assessing food quality that damage products, computer imaging systems (CISs) do not cause any damage to the product and use rapid analysis and in-line processing techniques. Another advantage of these systems is that they can be used to analyze an item, or a group of food items and agricultural products, such as fruits, even when not yet picked. Using IP, each feature's intensity analyzed at different times is determined (Tang \& Wen, 2009).

\subsection{Image processing and its main stages}

Machine vision is a system that has equipment and algorithms that can obtain information about the object. The information obtained from the item in question can be used for classification, quality recognition, identification of external and internal properties, etc. (Thinh et al., 2019). Obtaining item properties occurs through a series of steps. Imaging, pre-processing, image segmentation, representation, and explanation, recognition, and interpretation are the basis of the stages of machine vision processes and IP. For the final result to be satisfactory, each step must be done carefully (Gonzalez Viejo et al., 2016). With CIS, the electronic signal from the measuring device becomes numerical. Ultrasound, X-ray, near-infrared spectroscopy and document scanners, and other such devices use sensors to create digital images.

To get the right image, you need to use the right lighting and light combination; for this purpose, incandescent lamps, lasers, $\mathrm{X}$-rays, and infrared lamps are used. The pre-image processing step involves one or more operations to reduce noise, correct geometric shape, correct gravy area, and correct displacement to increase image quality. The IP system divides the image into parts. After segmentation, the image usually shows a border or an area. One type of image is suitable for analyzing size and shape, and the other type is used to determine the texture and defects of the image. The image display must be selected according to the intended application. Multilayer neural networks or statistical classifiers perform diagnosis and interpretation for IP. These categories are useful for determining the quality and degree of quality by processing and control machines. Genetic algorithm, decision tree, and fuzzy logic are some of the learning techniques used for this purpose (Wang et al., 2011).

\subsection{Applications of IP in food quality assessment and classification}

As mentioned earlier, with rising living standards, advances in technology and IP, and the growing importance of food quality, the FI has begun to use new technologies. On the other hand, as the population grows and consumer expectations rise more than ever, as well as their awareness, the FI needs fast and accurate analytical techniques. Producers need to market higher quality food and agricultural products to meet the complex demands of consumers. The IP systems are one of the advances in this field that has significantly contributed to the analysis of different food products and ensuring high-quality products. The IP systems can be used for different purposes, such as classifying products based on size and shape, detecting product defects, the presence of microbes, and grading food quality (Yu et al., 2018; Yong et al.,
2020). It can be said that IP systems in the FI have shown great potential. CISs can be used to sort products, detect defects, detect the internal and external properties of food, inspect food production equipment, and more. There is a wide range of programs for CISs that are becoming increasingly popular. In the following, we examine the evaluation of the quality of different foods and snacks by IP.

As mentioned earlier, assessing the safety and quality of food is vital for fresh foods such as vegetables, fruits, and meats. The quantitative assessment of fresh foods is especially essential. The external appearance of fresh fruits and vegetables is one of the factors affecting consumer perception. Since the first consumer perception is a visual perception and attention to the appearance, freshness, non-plasticity, and ripeness of the products, it is very important to consider these features when presenting the product to the market. Machine vision is a new tool for IP that determines quality depending on consumer demand. In this method, product packaging in terms of shape, defect detection, quality grading is possible. Some researchers have investigated the possibility of detecting contamination on the surface of apples using fluorescence imaging using hyperspectral linear scans and developed a simple multidimensional algorithm. To detect infected parts with different concentrations; They used a pair of red-purple linear lights. This algorithm uses four fluorescence densities in four wavebands $(680,684,720$, and 780$)$. With this method, more than $99 \%$ of infected spots have been identified in infected apples. The use of this system in the fast apple processing line, with the aim of preventing foodborne diseases, is possible to ensure the quality of food and reduce risks. Another group of researchers created a fast online scanning system with Vis / NIR reflectance and fluorescence in VIS. This system has a processing speed of three apples per second. Using fluorescence imaging and near-infrared reflection, excellent performance was achieved with $100 \%$ (no false positives) and $99.5 \%$ (only 2.2 false positives) detection rates of pesticides (Yang et al., 2011). Another very definitive imaging system was developed by ElMasry et al. (2008). In a new study, spots on apples were detectable. Stained apples were successfully identified from healthy apples.

Some properties of fruits and vegetables can be detected by machine vision without damaging the products. The amount of moisture, firmness, and softness and the $\mathrm{pH}$ value of cultural berry fruits can be determined by infrared imaging with a high correlation coefficient. To determine the level of ripeness of strawberries, cultural berry texture analysis was used based on the images obtained from the matrix of simultaneous occurrence of gray steps. The classification accuracy of this procedure was $89.61 \%$.

Another technique in IP is the use of thermal cameras. The purpose of this system was to monitor the process, adjust the heat vapor level and achieve uniformity on the surface parts of fruits such as carrots using a short steam method of 3 seconds. CISs are also used in the meat industry. These systems can be used to define some of the quality characteristics of fresh beef, such as meat color, $\mathrm{pH}$, and sensitivity to contaminants. Using a hyperspectral imaging system, the ability to detect contaminants such as feces and toxins on chicken and poultry carcasses was created. The system examines about 140 carcasses per minute. 


\section{Results and discussion}

As mentioned earlier, quality assurance is a vital target in any industry. The capability to produce high-quality and stable products is the basis of success in a highly competitive FI (Djekic \& Tomasevic, 2018). Quality assurance promotes honesty in customers and leads to the development of market share. Traditional methods of sensory evaluation are widely used in determining the quality of food and are still performed by trained inspectors. But these methods are time-consuming and costly. These factors have motivated alternative methods that evaluate the quality characteristics of the product in less time and more accurately. The IP is one of these methods (Kotsanopoulos \& Arvanitoyannis, 2017). The use of IP in measuring quality properties has been shown to be one of the most promising research topics (Gunasekaran, 1996; Du \& Sun, 2004; Aghbashlo et al., 2014).

Recently, computers are rapidly being used in the FI for quality assurance targets. In the last decade, the explosive growth of computer software and hardware has led to noteworthy advances in visual machine technology. The applications of the visual machine range from routine inspections to robotic controls. The IP is at the core of a visual computer that contributes to the wider applications of this technique by using more efficient algorithms. Computer vision that employed IP techniques has evolved rapidly to be able to quantitatively determine the complex size, shape, color, and texture of food (Brosnan \& Sun, 2004; Gomes \& Leta, 2012; Tretola et al., 2017).

The IP systems play a very significant role in food quality assessment. Computer vision is the technology of producing and analyzing images of a real scene by a computer in order to obtain information or control a process and a method of inspection that is fast, economical, stable, and non-contact. The speed and accuracy of this method have met its application in mass production and meeting the needs related to product quality control. This is why it has spread to many industries, especially automated processes, and replaced by visual inspection methods and so on. The need for this type of non-destructive and non-chemical inspection system, which eliminates direct human intervention, is felt more than other industries in the FI, which is directly related to the health of human society. The FI is now ranked among the top ten industries that use visual machine technology.

The CISs makes it easy to predict several external and internal quality elements and also to increase the safety and quality of food and agricultural products. Having a wide range of applications, cheapness, and usability in in-line processes and their flexibility has made CISs more attractive. It seems that further advances in technology and continuous development in CIS, machine vision will lead to a greater understanding of these systems and can meet the FI's growing needs. The requirement of any visual application is that the examined quality index can be seen in the image. Therefore, despite all the improvements in image analysis algorithms, camera performance and brightness of system components can have a significant impact on the reliability of the machine vision application. A well-designed lighting system can help improve the accuracy and results of image analysis by increasing image contrast. Good lighting will improve the detection of the quality index under consideration, shorten the processing time, and reduce the processing hardware requirements. That way, the lighting system will always be cheaper than the image processing system.

Computer vision has been widely used in the inspection and grading of fruits. Manual inspection of fruits is tedious and can cause eye strain. Inspection is also subject to sorting errors due to different judgments by different people. This process is still a challenge due to the complexity of the issue. For example, there are currently two major problems that prevent the apple from being graded automatically. One is how to capture the full surface image of an apple quickly on camera. Another problem is how to quickly identify the stem and part of the flower. Li et al. (2002) designed an experiment that could inspect the four sides of each apple simultaneously on the line (more than three to four apples per second). The installed system is shown in Figure 3.

A powerful area of research in image creation is the development of sensors. A wide variety of sensor combinations have been used to convert images into digital form. In the last decade, efforts have been made to develop non-destructive sensors to evaluate the composition and quality of food products. The same factor has caused that in recent years, sensor technology for assessing food products' quality and safety has been greatly developed. Different types of sensors such as charge-coupled device cameras, ultrasound, magnetic resonance imaging (MRI), electrical tomography, and computed tomography are widely used for imaging food products. However, in order to meet current demands with future technologies, there is still a lot of work to be done to solve the problems facing existing technologies. If this is the case, it is expected that the FI will use effective fusion technology to assess the safety and quality of food products worldwide (Zhang et al., 2017).

Today, robots are widely produced and used in industry and have become an essential element in large part of the production process. Many manufacturers rely on robots to improve productivity and product quality. Industrial robots were among the first robots to be designed because they were built for well-defined environments, thus simplifying robotic design work. These types of robots eventually replaced the simple manpower that performed repetitive tasks. Factory assembly lines can operate without the presence of humans and in a welldefined environment in which the robot must perform its tasks in a specific order and work on objects that are exactly in front of it. With the advancement of technology and the design of more advanced robots, industrial robotics allows various and more difficult tasks to be performed automatically on the production line and brings flexibility in this process. The horizon of robotic packaging application in the food industry is increasing to an incredible extent due to technological advances. Robots have the potential to change the processes involved in the processing and handling of food, packaging, pallets, and food. For this reason, in recent years, we have witnessed a growing trend of robots based in the food sector. In addition, robotics has become an integral part of the industry these days because of benefits such as increased operational efficiency, reduced material movements and Vehicle activity, and reduced stages of progress. Manufacturers of FI have shown a 25 percent increase in productivity after using 


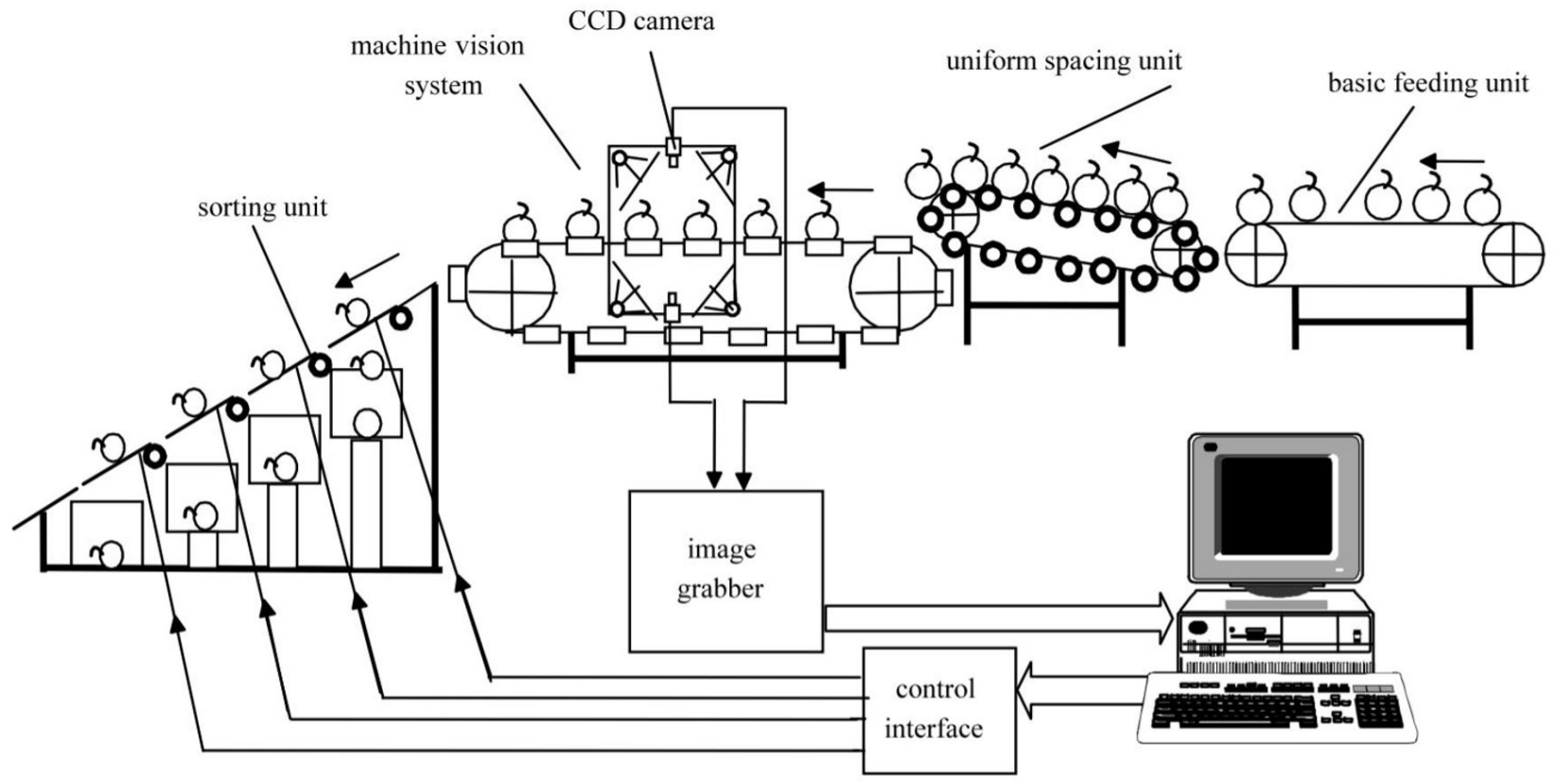

Figure 3. The application of computer vision in the representation of apple defects sorting system (Li et al., 2002).

robotics compared to work done by a human chain. According to Research and Markets, the global robot packaging market is expected to reach $\$ 4649$ million by 2023 .

\section{Conclusion}

The growing expectation of consumers to achieve high quality food with safety standards, the need for rapid, economical, nondestructive and hygienic inspection techniques as an alternative to traditional quality control methods is becoming increasingly apparent. IP is one of these methods that is used due to its satisfactory speed and accuracy and creating accurate descriptive data in agriculture and food industry, especially inspection and grading of fruits and vegetables, analysis of grain characteristics, evaluation of food and beverages. This article introduces the basic concepts and important elements of a computer vision based on IP and AI and discusses the applications of image analysis techniques in the food industry.

\section{References}

Aghbashlo, M., Hosseinpour, S., \& Ghasemi-Varnamkhasti, M. (2014). Computer vision technology for real-time food quality assurance during drying process. Trends in Food Science \& Technology, 39(1), 76-84. http://dx.doi.org/10.1016/j.tifs.2014.06.003.

Beyts, C., Chaya, C., Dehrmann, F., James, S., Smart, K., \& Hort, J. (2017). A comparison of self-reported emotional and implicit responses to aromas in beer. Food Quality and Preference, 59, 68-80. http://dx.doi. org/10.1016/j.foodqual.2017.02.006.

Bisgin, H., Bera, T., Ding, H., Semey, H. G., Wu, L., Liu, Z., Barnes, A. E., Langley, D. A., Pava-Ripoll, M., Vyas, H. J., Tong, W., \& Xu, J. (2018). Comparing SVM and ANN based machine learning methods for species identification of food contaminating beetles. Scientific Reports, 8(1), 6532. http://dx.doi.org/10.1038/s41598-018-24926-7. PMid:29695741.
Bouzembrak, Y., Steen, B., Neslo, R., Linge, J., Mojtahed, V., \& Marvin, H. J. P. (2018). Development of food fraud media monitoring system based on text mining. Food Control, 93, 283-296. http://dx.doi. org/10.1016/j.foodcont.2018.06.003.

Brosnan, T., \& Sun, D. W. (2004). Improving quality inspection of food products by computer vision--a review. Journal of Food Engineering, 61(1), 3-16. http://dx.doi.org/10.1016/S0260-8774(03)00183-3.

Buratti, S., Benedetti, S., \& Giovanelli, G. (2017). Application of electronic senses to characterize espresso coffees brewed with different thermal profiles. European Food Research and Technology, 243(3), 511-520. http://dx.doi.org/10.1007/s00217-016-2769-y.

Chu, B., Yu, K., Zhao, Y., \& He, Y. (2018). Development of noninvasive classification methods for different roasting degrees of coffee beans using hyperspectral imaging. Sensors (Basel), 18(4), 1259. http:// dx.doi.org/10.3390/s18041259. PMid:29671781.

Djekic, I., \& Tomasevic, I. (2018). Tools in improving quality assurance and food control. In A. M. Holban \& A. M. Grumezescu (Eds.), Handbook of Food Bioengineering. Food control and biosecurity (pp. 63-104). Academic Press http://dx.doi.org/10.1016/B978-012-811445-2.00003-9.

Du, C. J., \& Sun, D. W. (2004). Recent developments in the applications of image processing techniques for food quality evaluation. Trends in Food Science \& Technology, 15(5), 230-249. http://dx.doi.org/10.1016/j. tifs.2003.10.006.

ElMasry, G., Wang, N., Vigneault, C., Qiao, J., \& ElSayed, A. (2008). Early detection of apple bruises on different background colors using hyperspectral imaging. Lebensmittel-Wissenschaft + Technologie, 41(2), 337-345. http://dx.doi.org/10.1016/j.lwt.2007.02.022.

European Communities - EC. (2005). Commission Regulation No 2073/2005 of 15 November 2005 on microbiological criteria for foodstuffs. Official Journal of the European Communities (07/12/2007).

Fuentes, S., Tongson, E.J., De Bei, R., Gonzalez Viejo, C., Ristic, R., Tyerman, S., \& Wilkinson, K. (2019). Non-invasive tools to detect smoke contamination in grapevine canopies, berries and wine: a 
remote sensing and machine learning modeling approach. Sensors, 19(15), 3335. http://dx.doi.org/10.3390/s19153335.

Fuertes, G., Soto, I., Carrasco, R., Vargas, M., Sabattin, J., \& Lagos, C. (2016). Intelligent packaging systems: sensors and nanosensors to monitor food quality and safety. Journal of Sensors, 2016, 2016. http://dx.doi.org/10.1155/2016/4046061.

García-Esteban, J. A., Curto, B., Moreno, V., González-Martín, I., Revilla, I., \& Vivar-Quintana, A. (2018). A digitalization strategy for quality control in food industry based on Artificial Intelligence techniques. In Proceedings of the 2018 IEEE 16th International Conference on Industrial Informatics (INDIN) (pp. 221-226). USA: IEEE. http:// dx.doi.org/10.1109/INDIN.2018.8471994.

Ghafir, Y., China, B., Dierick, K., Dezutter, L., \& Daube, G. (2008). Hygiene indicator microorganisms for selected pathogens on beef, pork, and poultry meats in Belgium. Journal of Food Protection, 71(1), 35-45. http://dx.doi.org/10.4315/0362-028X-71.1.35. PMid:18236660.

Gomes, J. F. S., \& Leta, F. R. (2012). Applications of computer vision techniques in the agriculture and food industry: a review. European Food Research and Technology, 235(6), 989-1000. http://dx.doi. org/10.1007/s00217-012-1844-2.

Gonzalez Viejo, C., Fuentes, S., Li, G., Collmann, R., Condé, B., \& Torrico, D. Viejo, C. G., Fuentes, S., Li, G., Collmann, R., Condé, B., \& Torrico, D. (2016). Development of a robotic pourer constructed with ubiquitous materials, open hardware and sensors to assess beer foam quality using computer vision and pattern recognition algorithms: RoboBEER. Food Research International, 89(Pt 1), 504513. http://dx.doi.org/10.1016/j.foodres.2016.08.045. PMid:28460945.

Gonzalez Viejo, C., Torrico, D. D., Dunshea, F. R., \& Fuentes, S. (2019). Emerging technologies based on artificial intelligence to assess the quality and consumer preference of beverages. Beverages, 5(4), 62. http://dx.doi.org/10.3390/beverages5040062.

Gunasekaran, S. (1996). Computer vision technology for food quality assurance. Trends in Food Science \& Technology, 7(8), 245-256. http://dx.doi.org/10.1016/0924-2244(96)10028-5.

Guzmán, L. E. S., Acevedo, M. L. R., \& Guevara, A. R. (2019). Weedremoval system based on artificial vision and movement planning by $A^{\star}$ and RRT techniques. Acta Scientiarum. Agronomy, 41, e42687. https://doi.org/10.4025/actasciagron.v41i1.42687.

Iqbal, J., Khan, Z. H., \& Khalid, A. (2017). Prospects of robotics in food industry. Food Science and Technology, 37(2), 159-165. http:// dx.doi.org/10.1590/1678-457x.14616.

Ireri, D., Belal, E., Okinda, C., Makange, N., \& Ji, C. (2019). A computer vision system for defect discrimination and grading in tomatoes using machine learning and image processing. Artificial Intelligence in Agriculture, 2, 28-37. http://dx.doi.org/10.1016/j.aiia.2019.06.001.

Kaplan, A., \& Haenlein, M. (2019). Siri, in my hand: Who's the fairest in the land? On the interpretations, illustrations, and implications of artificial intelligence. Business Horizons, 62(1), 15-25. http://dx.doi. org/10.1016/j.bushor.2018.08.004.

Kotsanopoulos, K. V., \& Arvanitoyannis, I. S. (2017). The role of auditing, food safety, and food quality standards in the food industry: A review. Comprehensive Reviews in Food Science and Food Safety, 16(5), 760775. http://dx.doi.org/10.1111/1541-4337.12293. PMid:33371608.

Li, Q., Wang, M., \& Gu, W. (2002). Computer vision-based system for apple surface defect detection. Computers and Electronics in Agriculture, 36(2-3), 215-223. http://dx.doi.org/10.1016/S01681699(02)00093-5.

Liatsis, P., Goulermas, J. Y., Zeng, X. J., \& Milonidis, E. (2009). A flexible visual inspection system based on neural networks.
International Journal of Systems Science, 40(2), 173-186. http:// dx.doi.org/10.1080/00207720802630719.

Misra, N. N., Dixit, Y., Al-Mallahi, A., Bhullar, M. S., Upadhyay, R., \& Martynenko, A. (2020). IoT, big data and artificial intelligence in agriculture and food industry. IEEE Internet of Things Journal, http://dx.doi.org/10.1109/JIOT.2020.2998584.

Molajou, A., Afshar, A., Khosravi, M., Soleimanian, E., Vahabzadeh, M., \& Variani, H. A. (2021a). A new paradigm of water, food, and energy nexus. Environmental Science and Pollution Research International. http://dx.doi.org/10.1007/s11356-021-13034-1. PMid:33634401.

Molajou, A., Nourani, V., Afshar, A., Khosravi, M., \& Brysiewicz, A. (2021b). Optimal Design and Feature Selection by Genetic Algorithm for Emotional Artificial Neural Network (EANN) in Rainfall-Runoff Modeling. Water Resources Management, 35(8), 2369-2384. http:// dx.doi.org/10.1007/s11269-021-02818-2.

Nica, E., Janoškova, K., \& Kovacova, M. (2020). Smart Connected Sensors, Industrial Big Data, and Real-Time Process Monitoring in Cyber-Physical System-based Manufacturing. Journal of SelfGovernance and Management Economics, 8(4), 29-38. http://dx.doi. org/10.22381/JSME8420203.

Nourani, V., Molajou, A., Uzelaltinbulat, S., \& Sadikoglu, F. (2019). Emotional artificial neural networks (EANNs) for multi-step ahead prediction of monthly precipitation; case study: northern Cyprus. Theoretical and Applied Climatology, 138(3), 1419-1434. http:// dx.doi.org/10.1007/s00704-019-02904-x.

Patrício, D. I., \& Rieder, R. (2018). Computer vision and artificial intelligence in precision agriculture for grain crops: a systematic review. Computers and Electronics in Agriculture, 153, 69-81. http:// dx.doi.org/10.1016/j.compag.2018.08.001.

Pérez Santín, E., Rodríguez Solana, R., González García, M., García Suárez, M. D. M., Blanco Díaz, G. D., Cima Cabal, M. D., Rojas, J. M. M., \& Sánchez Lópes, J. I. (2021). Toxicity prediction based on artificial intelligence: a multidisciplinary overview. WIREs Computational Molecular Science, e1516.

Pouladi, P., Afshar, A., Molajou, A., \& Afshar, M. H. (2020). Sociohydrological framework for investigating farmers' activities affecting the shrinkage of Urmia Lake; hybrid data mining and agent-based modelling. Hydrological Sciences Journal, 65(8), 1249-1261. http:// dx.doi.org/10.1080/02626667.2020.1749763.

Qi, S. (2020). Cleaning system based on autonomous patrol of UAV and intelligent detection of foreign matters. In Proceedings of the 2020 7 th International Forum on Electrical Engineering and Automation (IFEEA) (pp. 675-678). USA: IEEE.

Romero, M., Luo, Y., Su, B., \& Fuentes, S. (2018). Vineyard water status estimation using multispectral imagery from an UAV platform and machine learning algorithms for irrigation scheduling management. Computers and Electronics in Agriculture, 147, 109-117. http://dx.doi. org/10.1016/j.compag.2018.02.013.

Sun, Q., Zhang, M., \& Mujumdar, A. S. (2019). Recent developments of artificial intelligence in drying of fresh food: A review. Critical Reviews in Food Science and Nutrition, 59(14), 2258-2275. http:// dx.doi.org/10.1080/10408398.2018.1446900. PMid:29493285.

Tang, A., \& Wen, A. (2009). An intelligent simulation system for earthquake disaster assessment. Computers \& Geosciences, 35(5), 871-879. http://dx.doi.org/10.1016/j.cageo.2008.03.003.

Thinh, N. T., Duc Thong, N., Cong, H. T., \& Thanh Phong, N. T. (2019). Mango classification system based on machine vision and artificial intelligence. In Proceedings of the 20197 th International Conference on Control, Mechatronics and Automation (ICCMA) (pp. 475-482). USA: IEEE. http://dx.doi.org/10.1109/ICCMA46720.2019.8988603. 
Tretola, M., Ottoboni, M., Di Rosa, A. R., Giromini, C., Fusi, E., Rebucci, R., Leone, F., Dell'Orto, V., Chiofalo, V., \& Pinotti, L. (2017). Former food products safety evaluation: computer vision as an innovative approach for the packaging remnants detection. Journal of Food Quality, 2017, 2017. http://dx.doi.org/10.1155/2017/1064580.

Wang, W., Peng, Y., Huang, H., \& Wu, J. (2011). Application of hyperspectral imaging technique for the detection of total viable bacteria count in pork. Sensor Letters, 9(3), 1024-1030. http://dx.doi. org/10.1166/sl.2011.1359.

Yang, C. C., Kim, M. S., Kang, S., Tao, T., Chao, K., Lefcourt, A. M., \& Chan, D. E. (2011). The development of a simple multispectral algorithm for detection of fecal contamination on apples using a hyperspectral line-scan imaging system. Sensing and Instrumentation for Food Quality and Safety, 5(1), 10-18. http://dx.doi.org/10.1007/ s11694-010-9105-1.

Yong, B., Shen, J., Liu, X., Li, F., Chen, H., \& Zhou, Q. (2020). An intelligent blockchain-based system for safe vaccine supply and supervision. International Journal of Information Management, 52, 102024. http://dx.doi.org/10.1016/j.ijinfomgt.2019.10.009.

Yu, K. H., Beam, A. L., \& Kohane, I. S. (2018). Artificial intelligence in healthcare. Nature Biomedical Engineering, 2(10), 719-731. http:// dx.doi.org/10.1038/s41551-018-0305-z. PMid:31015651.

Zhang, X., Zhang, J., Li, L., Zhang, Y., \& Yang, G. (2017). Monitoring citrus soil moisture and nutrients using an IoT based system. Sensors (Basel), 17(3), 447-456. http://dx.doi.org/10.3390/s17030447. PMid:28241488. 